\title{
DETECTION OF GASTROINTESTINAL LESIONS CAUSING IRON DEFICIENCY ANEMIA USINGGASTROINTESTINAL ENDOSCOPY
}

\author{
By
}

\section{Mohamed Refaat Abd El-Hafez, Helmy Ahmed Shalaby, Abd El-Aleem Abd El-Aleem El-Gendy and Mohamed Aly Abd El-Khalek Al-Boraie}

Department of Internal Medicine, Al-Hussein University Hospital, Faculty of Medicine, Al-Azhar University, Cairo, Egypt

Corresponding author: Mohamed Refaat Abd El-Hafez,

Mobile: 01007521186, E-mail: mohamed.7022@yahoo.com

\begin{abstract}
Background: Anemia is a major world-wide health problem. Iron deficiency anemia (IDA) is a common manifestation of most of the gastrointestinal lesions.

Objective: Evaluation of the role of gastrointestinal endoscopy in detecting the causes of iron deficiency anemia.

Patients and Methods: Fifty patients with Iron deficiency anemia with no obvious cause participated in this study during the period from April 2019 to October 2020. They presented to the Department of Internal Medicine, Al-Hussein University Hospital, and referred for gastrointestinal endoscopy.

Results: Thirty eight patients $(76 \%)$ of the 50 studied anemic patients had gastrointestinal lesions detected by either esophagogastroduodenoscopy (EGD), or colonoscopy or both of them.

Conclusion: Iron deficiency anemia is a common manifestation of most of the gastrointestinal lesion. Gastrointestinal endoscopy is a very valuable investigation in the diagnosis of the causes of iron deficiency anemia.
\end{abstract}

Keywords: Iron deficiency anemia, gastrointestinal endoscopy.

\section{INTRODUCTION}

Approximately, one-half of anemia is a result of iron deficiency anaemia. Iron deficiency is defined as the decrease of the total content of iron in the body (Guralink et al., 2014).

Iron deficiency anemia occurs when iron deficiency is sufficiently severe to reduce erythropoiesis. This type of anemia is the most frequent chronic anemia. Iron deficiency may be the result of either excessive loss or, less frequently, decreased absorption (Johnson-Wimbley, 2011).

Iron deficiency, with or without anemia, is often caused by digestive diseases and should always be investigated, as its causes could be serious diseases such as cancer (McIntyre and long, 2012).

The development of iron deficiency, and the rapidity with which it progresses depends mainly on the individual's initial iron stores, which are, in turn, dependent 
on age, sex, rate of growth, and the balance between iron absorption and loss (Looker et al., 2013). The major cause of iron deficiency is blood loss; either overt or occult (Cook, 2014).

It is sometimes difficult to differentiate iron deficiency anemia from anemia of chronic diseases which can coexist. In this case, other parameters such as soluble transferrin receptor activity can be very useful. After an initial evaluation by clinical history, full laboratory tests for iron deficiency, gastroscopy and colonoscopy are the key diagnostic tools for investigating the origin of iron deficiency, and detect the most important and prevalent diseases (Beutler et al., 2012).

Gastric and duodenal ulcers usually cannot be differentiated based on history alone. Epigastric pain is the most common symptom of both gastric and duodenal ulcers. It is characterized by a gnawing or burning sensation and occurs after meals classically, shortly after meals with gastric ulcer and 2-3 hours afterward with duodenal ulcer (Chey et al., 2014).

Esophagogastroduodenoscopy is the preferred diagnostic test in the evaluation of patients with signs or symptoms suggestive of upper gastrointestinal disease as dyspepsia, dysphagia and noncardiac chest pain (Lai et al., 2016).

Diagnostic EGD is considered a lowrisk procedure for bleeding in patients on anticoagulants and, therefore, can be performed without adjustment of anticoagulants (Ben-Menachem et al., 2012).

Smoking is associated with an increased incidence of stomach cancer in a dose dependent manner, both for the number of cigarettes and for duration of smoking. A meta-analysis of 40 studies estimated that the risk was increased by approximately 1.5 to 1.6 fold and higher in men (Haseman et al., 2014).

Colonoscopy enables visual inspection of the entire large bowel from the distal rectum to the cecum. The procedure is a safe and effective means of evaluating the large bowel (Samarasena et al., 2012).

Inflammatory bowel disease (IBD) is an idiopathic disease caused by a dysregulated immune response to host intestinal microflora. The 2 major types of IBD are ulcerative colitis, which is limited to the colon, and Crohn's disease, which can involve any segment of the gastrointestinal tract from the mouth to the anus. There is a genetic predisposition for IBD, and patients with this condition are more prone to the development of malignancy (Marmo et al., 2014).

If esophagogastroduodenoscopy and colonoscopy are normal and anemia is not severe, treatment with oral iron can be indicated, along with stopping any treatment with non-steroidal antiinflammatory drugs. In the absence of response to oral iron, or if the anemia is severe or clinical suspicion of important disease persists, we must insist on diagnostic evaluation. Repeated endoscopic studies should be considered in many cases and if both still show normal results, investigating the small bowel must be considered. The main technique in this case is enteroscopy (Yates and Cook, 2013). 


\section{PATIENTS AND METHODS}

This study was conducted on 50 patients referred for gastrointestinal endoscopy at Al-Hussien University Hospital from April 2019 to October 2020. Their ages ranged between 17 and 82 years old (27 patients were males and 23 patients were females).

Inclusion Criteria: Patients who were anemic and proved to have iron deficiency anemia with no obvious cause, hemoglobin concentration of $12 \mathrm{gm} / \mathrm{dL}$ or less for men, and $11 \mathrm{gm} / \mathrm{dL}$ or less for women, with hypochromic microcytic indices, serum of iron $45 \mathrm{mcg} / \mathrm{dL}$ or less, hemodynamically stable and they agree to participate in the study and sign informed consent.

Exclusion criteria: Any patients receiving treatment for any gastrointestinal diseases, or any contraindications for esophagogastroduodenoscopy (possible perforation, medically unstable patients, severe thrombocytopenia), or colonoscopy (e.g. suspected colonic perforation, toxic megacolon and fulminant colitis), or patients refusing to participate in the study.

All patients underwent evaluation in the form of complete history taking, full physical examination including general, abdominal examination and vital signs, blood tests in form of complete blood picture, serum iron, serum ferritin, reticulocyte count.

Esophagogastroduodenoscopy was performed while the patient was under moderate sedation as propofol. General anesthesia was often used in a selected group of patients. It can be performed without adjustment of anticoagulants prior to the procedure.

Colonoscopy enables visual inspection of the entire large bowel from the distal rectum to the cecum. The technology for colonoscopy has evolved to provide a very clear image of the mucosa through a video camera attached to the end of the scope. The camera connected to a computer, which can store and print color images selected during the procedure.

\section{Statistical analysis:}

Data were collected, revised, coded and entered into the statistical package for the Social Science (IBM SPSS) version 23 (IBM Corp., Armonk, New York, USA). The quantitative data were presented as mean, standard deviations and ranges, and were compared by independent t-test. Qualitative data were presented as numbers and percentages. So, the p-value was considered significant at $\mathrm{p}<0.05$. using

Mann-whitney V test. 


\section{RESULTS}

In this study, 50 patients were included. Their ages ranged between $17-$ 82 years old $($ mean $=45.1$ years $)$. Twenty seven patients were males and 23 patients were females who underwent esophagogastroduodenoscopy and/or colonoscopy (Table 1).

\section{Table (1): Sex distribution of our patients}

\begin{tabular}{|c|c|c|}
\hline & Number & Percent \\
\hline Male & 27 & $54 \%$ \\
\hline Female & 23 & $46 \%$ \\
\hline Total & 50 & $100 \%$ \\
\hline
\end{tabular}

Laboratory tests were performed revealing microcytic hypochromic anemia which were confirmed by iron studies that revealed $\mathrm{Fe}$ deficiency anemia. Comparison between males and females as regards laboratory findings revealed no statistically significant differences ( $p$ value > 0.5). Laboratory data of our patients and comparison between males and females (Table 2).

Table (2): Comparison between males and females as regards Laboratory data of our patients

\begin{tabular}{|c|c|c|c|c|}
\hline & Mean \pm SD & Minimum & Maximum & P value \\
\hline Hb $(\mathbf{g} / \mathbf{d l})$ & & & & \\
Males & $9.88 \pm 9.86$ & 8.6 & 11.0 & \\
Females & $0.61 \pm 0.62$ & 8.4 & 10.7 & \\
MCV (fl) & & & & \\
Males & $67.6 \pm 68.4$ & 47 & 77.0 & \multirow{2}{*}{$\mathbf{0 . 0 5}$} \\
Females & $10.1 \pm 9.1$ & 49 & 77.0 & \\
Serum Iron $(\boldsymbol{\mu g} / \mathbf{d L})$ & & & & \\
Males & $35.7 \pm 34.8$ & 23 & 45.0 & \\
Females & $7.14 \pm 5.77$ & 19 & 42.0 & \\
Ferritin $(\boldsymbol{\mu g} / \mathbf{L})$ & & & & \\
Males & $14.7 \pm 14.0$ & 9 & 24.0 & \\
Females & $3.3 \pm 3.9$ & 7 & 23.4 & \\
\hline
\end{tabular}

Patients were divided into 2 groups (A and B). Group A included 12 patients (24\%) didn't have any lesions detected, and they were referred to further investigations, whereas group B included 38 patients $(76 \%)$ had gastrointestinal lesions detected by either esophagogastroduodenoscopy or colonoscopy or both gastrointestinal endoscopy. There was a statistically significant difference between patients with and without detected lesions as regards age 48.3 years +15.6 in patients with lesion versus 35.2 years +8.12 in patients without lesion. There was no statistically significant difference between patients with and without detected lesions as regards haemoglobin, serum iron and serum ferritin (Table 3). 
Table (3): Comparison between group $A$ and group $B$ as regards age and laboratory data

\begin{tabular}{|c|c|c|c|}
\hline & $\begin{array}{c}\text { Group A } \\
\mathbf{N = 1 2}\end{array}$ & $\begin{array}{c}\text { Group B } \\
\mathbf{N = 3 8}\end{array}$ & \multirow{2}{*}{ P value } \\
\hline Age (years) & $35.2 \pm 8.12$ & $48.3 \pm 15.6$ & 0.008 \\
\hline Hb \% & $10.06 \pm 0.45$ & $9.7 \pm 0.64$ & \multirow{2}{*}{$>0.05$} \\
\cline { 1 - 3 } Serum iron $(\boldsymbol{\mu g} / \mathbf{d L})$ & $35.7 \pm 5.9$ & $35.1 \pm 6.5$ & \\
\hline Ferritin $(\boldsymbol{\mu g} / \mathbf{d})$ & $15.57 \pm 3.48$ & $13.92 \pm 3.66$ & \\
\hline
\end{tabular}

After esophagogastroduodenoscopy and colonoscopy for our patients, results revealed that:

38 patients $(76 \%)$ of the 50 studied anemic patients had gastrointestinal lesions detected by either EGD or colonoscopy or both gastrointestinal endoscopy. 12 patients (24\%) didn't have lesions detected by EGD or colonoscopy and they were referred to further investigations. Lesions were detected by EGD in 33 patients; of them 4 patients had also colonoscopy detected lesions. So, patients with only EGD lesions were 29 patients. Lesions were detected by colonoscopy in 9 patients; of them 4 patients had also EGD detected lesions.
So patients with only colonoscopy lesions were 5 patients. Combined lesions in both upper and lower gastrointestinal tract were present in 4 patients. So, EGD and colonoscopy can find a cause of iron deficiency anemia in $76 \%$ of cases. So, peptic ulcer disease (gastric and duodenal) represented the most prevalent upper gastrointestinal lesions $(23.5 \%)$ in cases of iron deficiency anemia followed by cancer stomach, angiodysplasia and esophageal cancer. Colorectal cancer diseases represented the most prevalent lower gastrointestinal lesions in cases of iron deficiency anemia (10.5\%) followed by angiodysplasia, internal piles and ulcerative colit (Figures 1, 2).

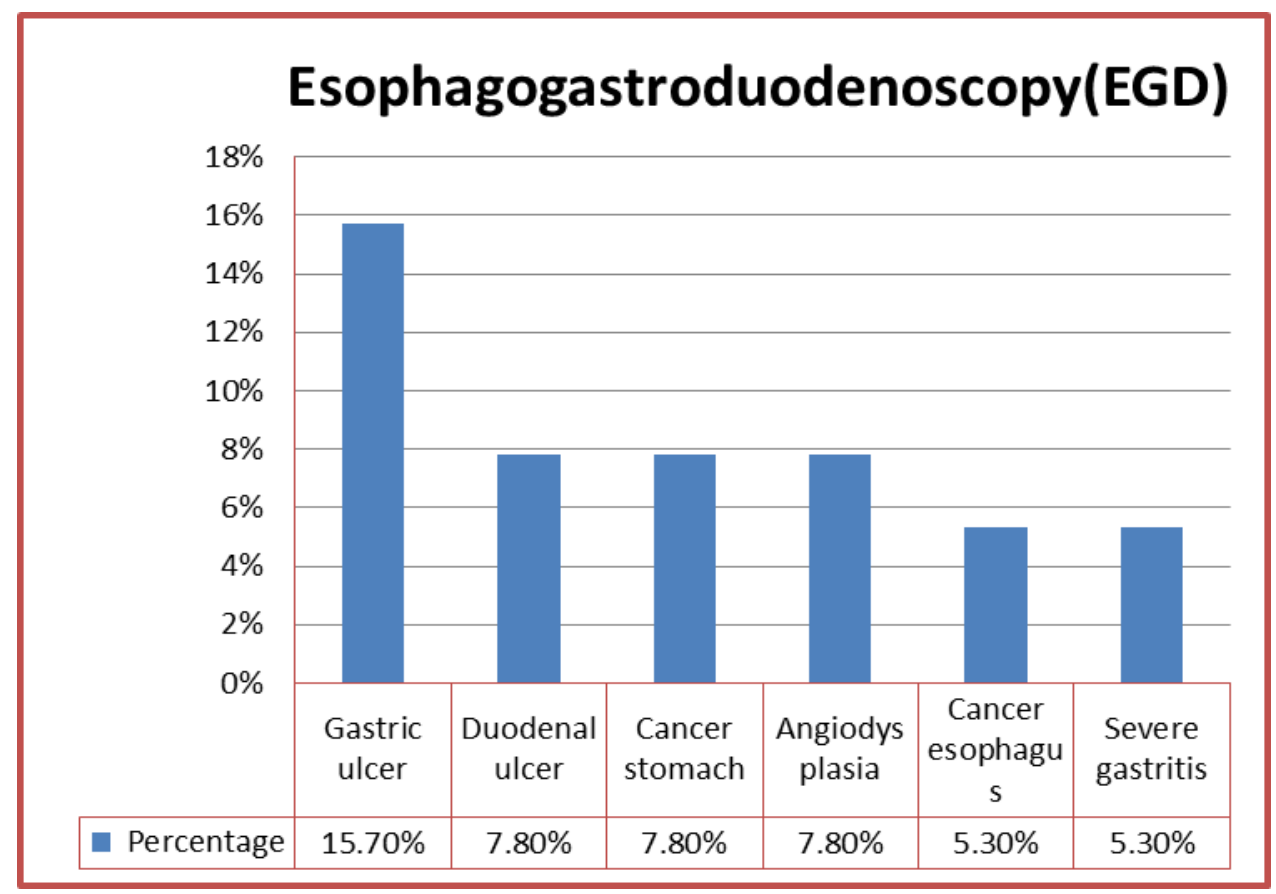

Figure (1): Percentage of detected lesions by EGD 


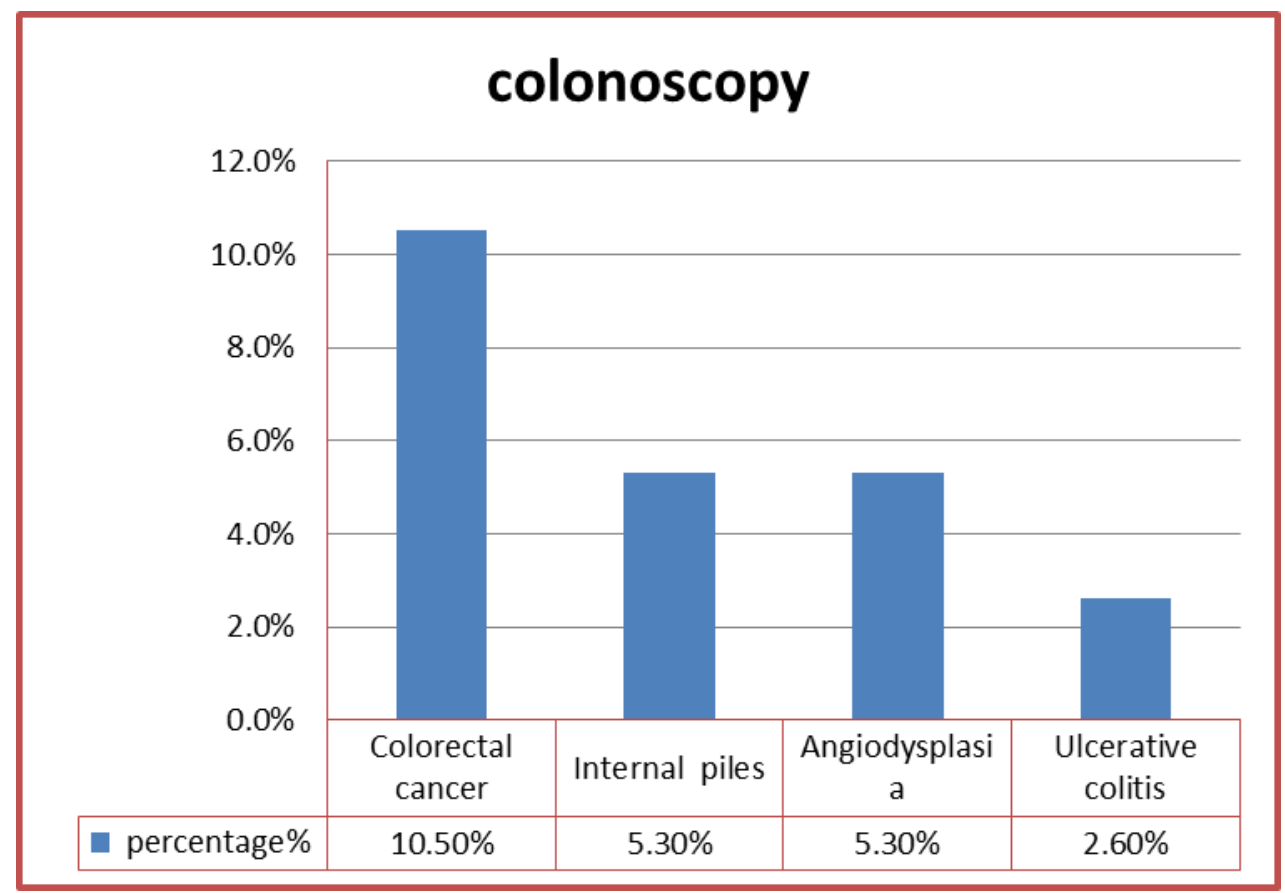

Figure (2): Percentage of detected lesions by colonoscopy

\section{DISCUSSION}

Our study revealed that patients $76 \%$ had gastrointestinal lesions detected by esophagogastroduodenoscopy

or colonoscopy, while $24 \%$ had no GIT lesions. They were males $54 \%$ and females $46 \%$. Upper gastrointestinal lesions were detected in $58 \%$ while lower gastrointestinal lesions were present in $10 \%$. Combined lesions in both upper and lower gastrointestinal were present in $8 \%$.

Our results agreed with Annibale and Colleagues (2013) who revealed a likely cause of iron deficiency anemia was detected in $85 \%$ and undetected in $15 \%$.

Another study was carried out by $\mathrm{El}$ Sayed (2012) reveled angiodysplasia in $11.85 \%$ the second common cause of iron deficiency anemia after peptic ulcer was $39.8 \%$ detected by esophagogastroduodenoscopy in the Egyptian society. But his study didn't include any lower gastrointestinal lesions caused in iron deficiency anemia as the patients were not subjected to colonoscopy.

In our study, there were significant relations between age, $\mathrm{Hb}$, TIBC and iron deficiency anemia patients especially in patients with detected lesions than those with no detected lesions as gastrointestinal lesions is higher in older age with lower $\mathrm{Hb} \%$

About 24\% with iron deficiency anemia who were subjected to our study revealed no gastrointestinal abnormalities in their EGD and colonoscopy indicating that still there was a percentage of the patients with iron deficiency anemia could not be diagnosed by esophagogastroduodenoscopy and colonoscopy which necessitates further diagnostic procedures. 
Iron deficiency, with or without anemia, is often caused by digestive diseases and should always be investigated, as its causes could be serious diseases such as cancer. Gastrointestinal malignancies are very common in Iron deficiency anemia patients especially old age.

\section{CONCLUSION}

Gastrointestinal lesions in both the upper gastrointestinal tract and the colon are frequently found in patients with iron deficiency anemia. Esophagogastroduodenoscopy and colonoscopy are very valuable investigations in the diagnosis of the causes of iron deficiency anemia.

Peptic ulcer diseases remain the first common upper gastrointestinal lesion. Alarm symptom as heartburn, dysphagia, recurrent vomiting with no improvement after therapeutic trial of proton pump inhibitor therapy twice daily for 4 to 8 weeks should consider in esophagogastroduodenoscopy.

\section{REFERENCES}

1. Annibale B, Capurso $\mathbf{G}$ and Chistolini $\mathbf{A}$. (2013): Gastrointestinal causes of refractory iron deficiency anemia in patients without gastrointestinal symptoms. Am J Med., 24: 111-439.

2. Ben-Menachem T, Decker GA and Evans JA. (2012): Appropriate use of GI endoscopy. Gastrointest Endosc., 75 (6): 1127-31.

3. Beutler E. (2012): Diagnosis of irondeficiency anemia in the elderly. Am J Med., 145: 88-205.

4. Chey WD, Wong CY and American College of Gastroenterology (2014): Guideline on the management of helicobacter pylori infection. Am J Gastroenterol., 102 (8): 1808-25.
5. Cook JD. (2014): Iron deficiency: definition and diagnosis. J Intern Med., 25: 226-349.

6. El-Sayed S (2012): Role of endoscopy in diagnosis of gastrointestinal lesions causing Fe deficiency anemia in Egyptian society. Menoufia Med J., 33:217-21.

7. Johnson-Wimbley TD. (2011): Diagnosis and management of iron deficiency anemia in the 21st century. Therap Adv Gastroenterol. 2011 May; 4(3): 177-184.

8. Guralnik JM, Eisenstaedt RS and Ferrucci L. (2010): Prevalence of anemia in persons 65 years and older in the United States: evidence for a high rate of unexplained anemia. Blood, 24: 104:2263.

9. Haseman JH, Lemmel JT and Rahmani EY. (2014): Smoking and the risk of gastric cancer in the European Prospective Investigation In to Cancer and Nutrition (EPIC). Int J Cancer, 107(4): 629-34.

10. Lai KC, Lam SK and Chu KM. (2016): Lansoprazole for the prevention of recurrences of ulcer complications from long term lowdose aspirin use. N Engl J Med., 346(26): 2033-8.

11. Looker AC, Dallman PR and Carroll MD. (2013): Prevalence of iron deficiency in the United States. JAMA, 54: 277-973.

12. Marmo R, Rotondano $G$ and Piscopo R. (2014): Meta-analysis: capsule enteroscopy vs. conventional modalities in diagnosis of small bowel diseases. Aliment Pharmacol Ther., 22: 595-604.

13. McIntyre AS and Long RG. (2011): Gastrointestinal causes of refractory iron deficiency anemia in patients without gastrointestinal symptoms. Am J Med., 111: 439-46.

14. Samarasena JB, Muthusamy VR and Jamal MM. (2012): Split-Dosed MiraLAX/Gatorade Is an Effective, Safe, and Tolerable Option for Bowel Preparation in Low-Risk Patients: A Randomized Controlled Study. Am J Gastroenterol., 107(7):1036-42. 
15. Yates JM and Cook JD. (2013): Diagnosis and management of iron-deficiency anaemia. Best Pract Res Clin Haematol., 18: 319-324. 


\section{تحديد أمر اض الجهاز الهضمي المتسببه في نقص الحديد بواسطة مناظير الجهاز الهضدي}

محمد رفعت عبد الحافظ, حلمى أحمد شلبي, عبد العليم عبد العليم الجندي, محمد علي

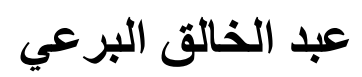

قسم الباطنة العامة, كلية الطب, جامعة الأزهر

E-mail: mohamed.7022@yahoo.com

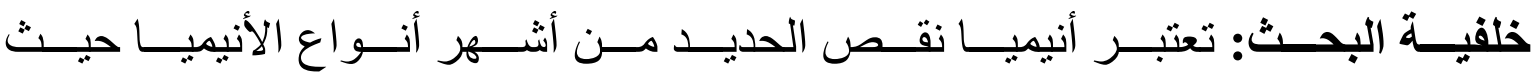

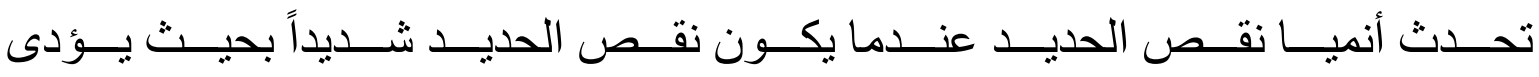

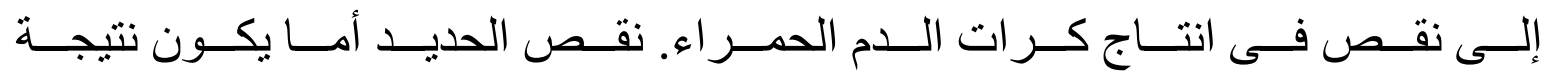

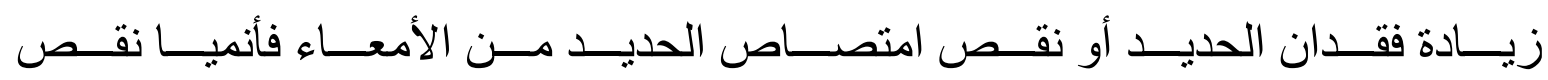
الحديد تحدث فى الرجال و السيدات و الأطفال و كبار السن.

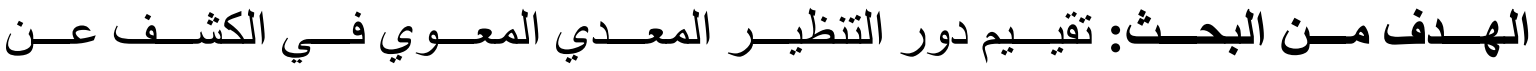
أسباب فقر الدم الناجم عن نقص الحديد.

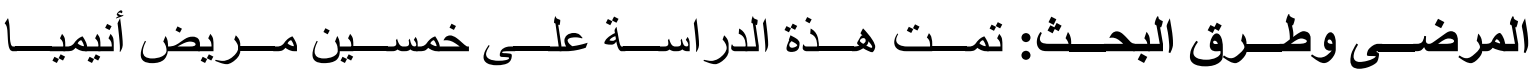

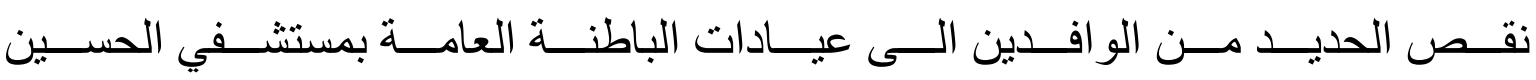

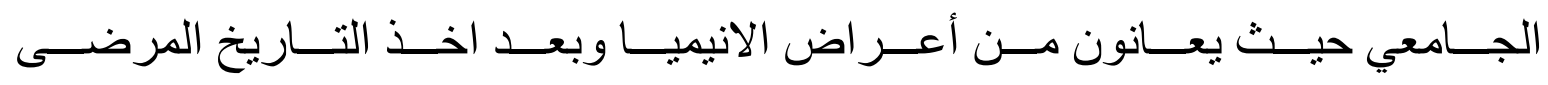

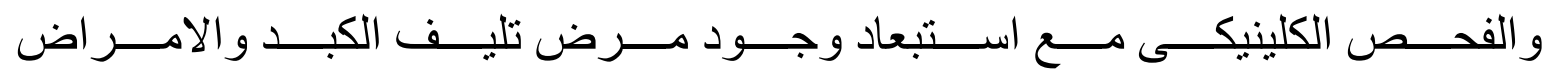

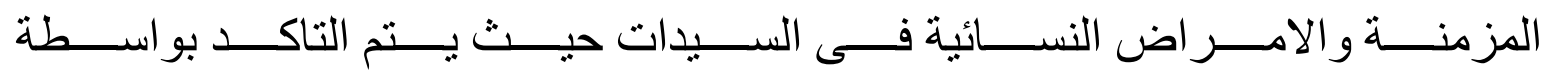

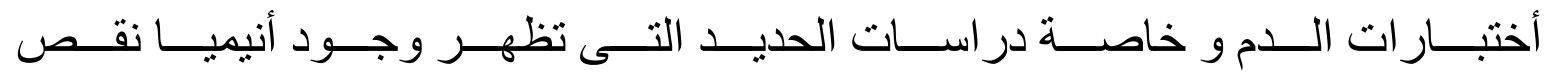

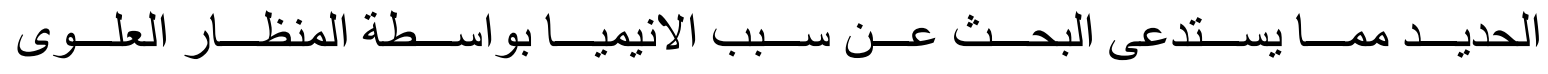

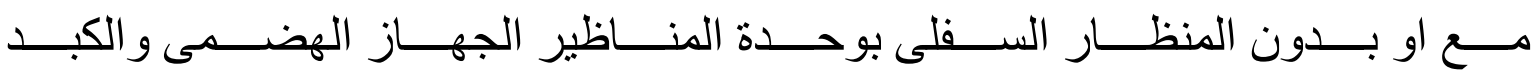

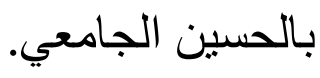




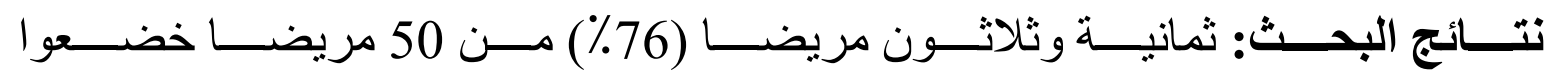

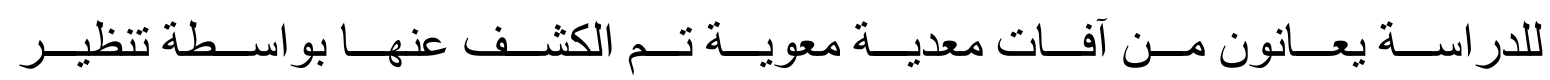
المريء أو تتظير القولون أو كليهما.

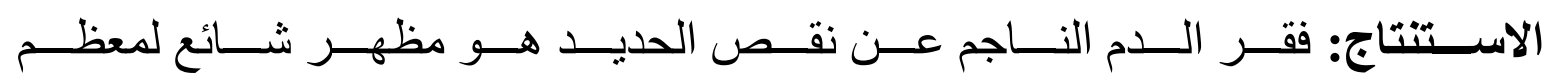

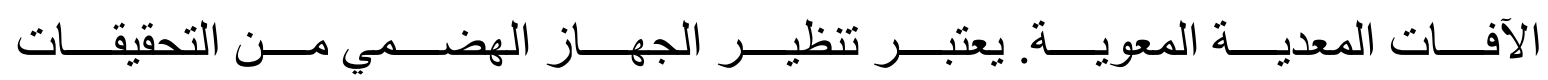
القيمة للغاية في تشخيص أسباب فقر الدم بسبب نقص الحديد.

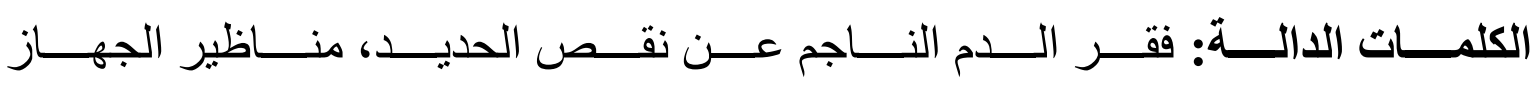
الهضمي. 